\title{
MODELING AND SIMULATION OF SUCTION BLOW MOLDING PROCESS FOR PRODUCING CURVED DUCTS
}

\author{
KALONJI K. KABANEMI' AND JEAN-PHILIPPE MARCOTTE ${ }^{2}$ \\ ${ }^{1}$ National Research Council of Canada \\ 75 De Mortagne Blvd., Boucherville, QC, J4B 6Y4, Canada \\ kalonji.kabanemi@nrc.ca \\ ${ }^{2}$ National Research Council of Canada \\ 75 De Mortagne Blvd., Boucherville, QC, J4B 6Y4, Canada \\ Jean-Philippe.Marcotte@cnrc-nrc.gc.ca
}

Key words: Suction Blow Molding, Large Deformation, Fluid-Structure Interaction, Viscoelastic Model.

\begin{abstract}
During suction blow molding process, the extruded parison undergoes twisting deformation within the mold cavity, as the air drawing flow around the deforming parison exerts non-uniform shear stresses on its surface. This research is devoted in developing a fluid-structure interaction model for predicting parison deformation during suction blow molding process, with a specific emphasis on the suction stage. A fluid flow model, based on Hele-Shaw approximations, is formulated to simulate the air drag force exerted on the parison surface. The rheology of the polymer during suction is assumed to obey the K-BKZ integral viscoelastic model. The numerical results of this study allowed identifying a clear correlation between the twisting deformation undergone by the parison during the suction stage, also observed experimentally and the design parameters, namely, the air suction speed, the geometry of the duct mold cavity, and the parison/mold eccentricity.
\end{abstract}

\section{INTRODUCTION}

Parison suction blow molding process is commonly used to economically produce elongated and complex curved 3D hollow parts, as a single plastic piece that cannot be achieved by other processes [1-2]. In this process, the mold parts first close together so as to form the cavity defining the contour of the final tubular body. Then the parison is extruded from the die into the closed cavity. The parison floats on an air stream generated by a suction device at the exit of the cavity. The parison is drawn down through the mold contours, while support air flow is blown inside the parison from the upper end to prevent collapsing of the parison. When the mold is filled, sliders close the upper and lower ends of the parison. The parison is inflated against the cavity walls by needles located at the parison ends. A schematic view of the process is shown in Figure 1. Applications of the suction process in automotive sector include fuel filler pipes, convoluted coolant pipes, and air ducts.

(C) 2021 National Research Council of Canada 
To date, numerical modeling of the suction blow molding process is almost inexistent in the scientific literature. In a recent survey, we found no scientific publications in this area, most publications addressing the die swell simulation problem $[3,4]$ and the modeling of extrusion blow molding process [5,6], among others. During the extrusion process, the parison swells and sags as it exits the die. The prediction of the annular swell from classical conservation principles is difficult because of the free surface present, the viscoelastic behavior of the polymer, the time dependent nature of the swell and the die gap profile.
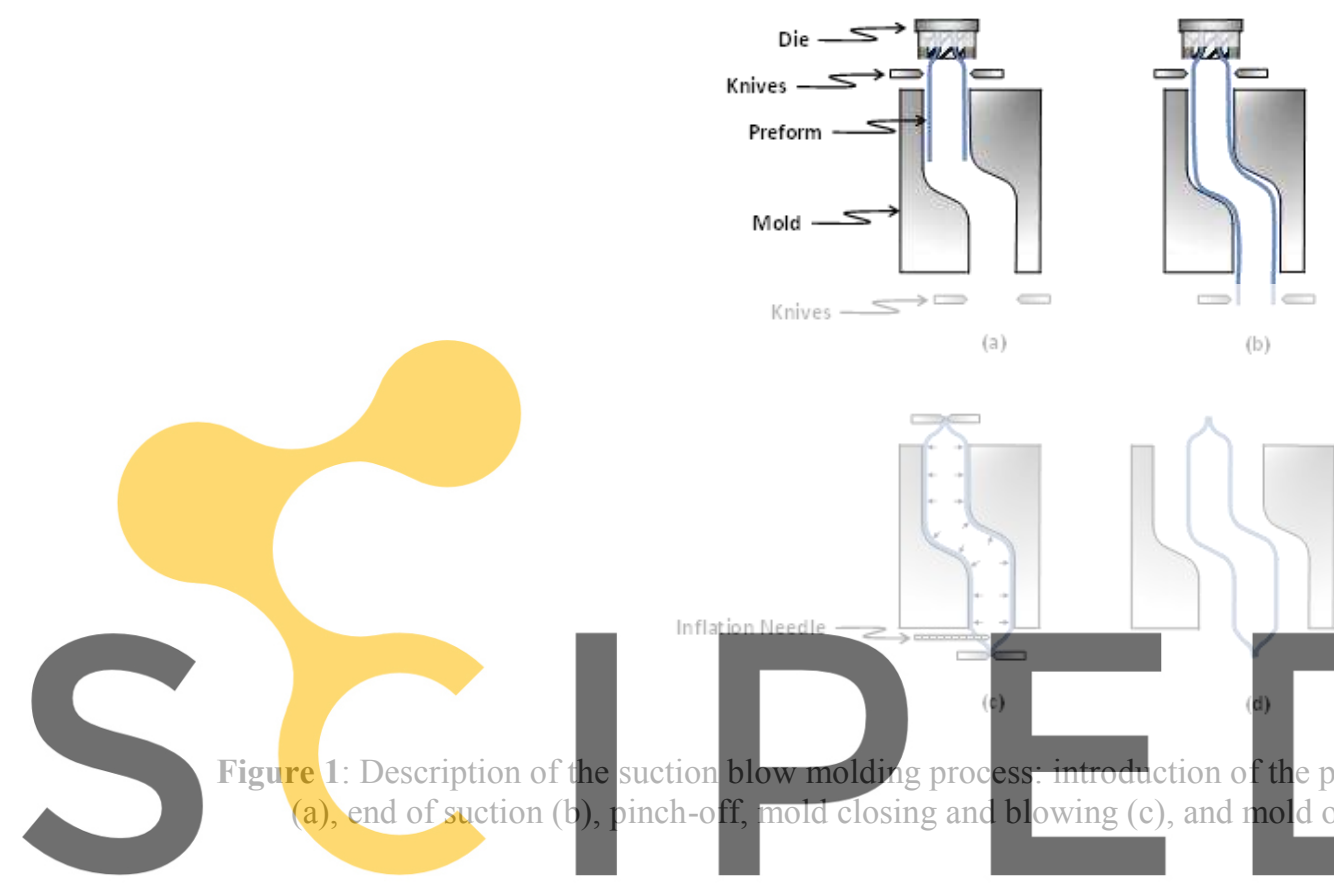

b)

Whereas in extrusion blow molding process the parison is extruded to the desired length

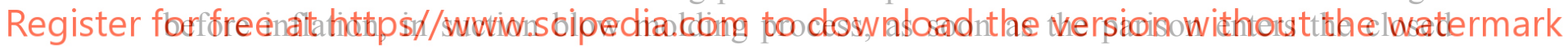
duct mold, it is simultaneously drawn down through the mold contours by the surrounding high-speed air flow generated at the mold exit as illustrated in Figure 2.

In this study, we have been interested in understanding the role of the air flow stream, the mold cavity geometry and the initial parison thickness generated during extrusion on the final thickness distribution of the hollow body. These design parameters could affect the deformation undergone by the parison within the mold cavity during suction. In this regard, numerical modeling can give useful insight in the overall process stages and help defining optimal design parameters to ensure more appropriate final wall thickness distribution of the duct part.

In our previous work [5], the integrated modeling of the conventional extrusion blow molding process was conducted. The individual process phases, namely, parison formation, inflation and solidification were simulated in sequence.

In the present work the focus is put on the suction phase exclusively, with an emphasis on the prediction of twisting deformation undergone by the parison within the duct mold cavity and the prediction of the wall thickness distribution at the end of suction process. The objective is to relate the final thickness distribution of the hollow body to key design parameters, i.e., the air drawing speed, the geometry of the mold cavity and the initial parison 
thickness generated during extrusion.

For the sake of clarity, we will find it useful to recall the basic equations for the model problem shown in Figure 2, along with the numerical techniques used. A thorough description of the basic equations for the suction blow molding problem has been given by Kabanemi and Marcotte [2].

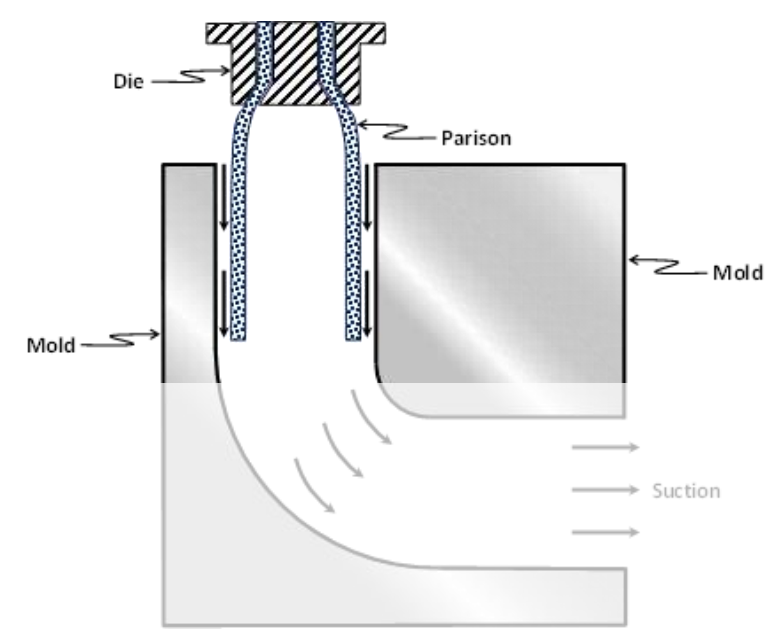

Figure 2: Schematic view of the suction process.
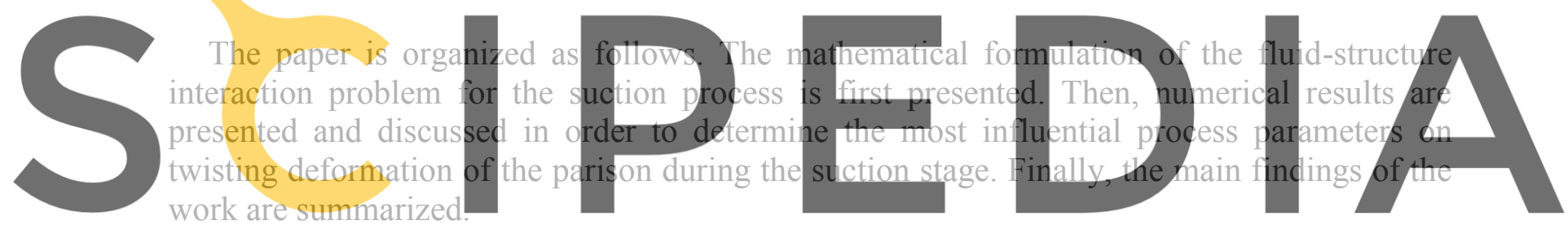

\section{Register for free at https//www.scipedia.com to download the version without the watermark 2 MATHEMATICAL FORMULATION}

The simulation of the parison suction requires the coupled solution of the fluid and structure interaction problems. During the process, the parison is subject to a high speed air flow within the mold cavity (Figure 2). As a result, shear stresses or forces appear on the parison surface. These forces deform the parison and consequently the air flow domain. The air flow domain, i.e., the gap between the mold cavity surface and the parison free surface, changes continuously during the suction blow molding as the parison deforms and slides within the mold cavity. Because the fluid and solid interact through the air drag forces on the parison and through the deforming annular air flow domain, information has to be exchanged between both models (fluid and structure) at every time step.

\subsection{Air flow model and air drag force}

Whenever a body is placed in a flow, it is subjected to a force from the surrounding fluid. In the suction process, the external force is provided by a high-speed air stream interacting with the parison free surface. This section is devoted in developing a model that calculates the air drag force acting on the parison surface. 
The parison is hung vertically in the center of a duct mold, and is supported at the upper end (die-head) and free at the lower one. Fluid flows downward in a relatively narrow annular space (Figure 3). Motions of the parison in the confining duct mold are fully threedimensional. It is assumed that the thickness of the annular air flow domain, i.e., the gap between the mold cavity surface and the parison free surface, is small in comparison with the characteristic dimensions of the annular air flow domain. The flow state in the annulus, which may be laminar flow or turbulent flow depending on the behavior of the main flow and the disturbance level, strongly influences the parison deformation in the mold and the performance of the suction process. The determination of the critical condition for the flow transition in annulus is therefore of great interest. Such a critical condition for turbulent transition in annulus flow has been calculated by Dou et al. [7]. As long as the Reynolds number Re is below the critical value, the flow in the annulus can be maintained as a laminar flow regardless of the level of disturbance. This assumption is made in the sequel.

As a result, a fluid flow model, based on the Hele-Shaw approximation for thin cavities [8] is used to predict the air drag force exerted on the parison surface. In our model, the thin annular air flow domain, bounded by the parison free surface and the mold cavity surface, is fully defined by its midsurface and the local gap-wise thickness. The sketch of the problem is shown in Figure 3. At any point $\mathrm{P}^{*}$ of the midsurface, an orthonormal frame $(\xi, \theta, \zeta)$ is defined such that $\mathrm{P} * \zeta$ is normal to the midsurface. This implies that $\mathrm{P}^{*} \xi$ and $\mathrm{P}^{*} \theta$ are tangent to the latter surface as shown in Figure 3. In our formulation, $\mathrm{P}^{*} \theta$ is oriented to the circumferential direction while $P^{* \xi}$ is priented to the stretching direction. Finally, the gap thiekness of the
annular air flow domain is a function of the position of the midsurface, $\mathrm{e} . \mathrm{e}, \mathrm{h}=\mathrm{h}(\xi, \theta)$ and
assumed to have a smooth variation.
By averaging the continuity equation over the gap of the annular air flow domain, one
obtains the resulting boundary value problem in the midsurface, given by the Hele-Shaw
equation ( $\nabla$ stands for the gradient operator in the reference frame system):

Register for free at https//www.scipedia.comb to downtload the version without the watermark

where $p$ is the pressure and $S_{F L}=h^{3} / 3 \eta$ is the fluidity parameter. The shear rate is approximatively given by:

$$
\dot{\gamma}(\varsigma)=\left\|\frac{\partial \underline{\mathrm{u}}_{\mathrm{m}}}{\partial \zeta}\right\|=\sqrt{\left(\frac{\partial \mathrm{u}_{\xi}}{\partial \zeta}\right)^{2}+\left(\frac{\partial \mathrm{u}_{\theta}}{\partial \varsigma}\right)^{2}}=\frac{\varsigma}{\eta} \sqrt{\left(\frac{\partial \mathrm{p}}{\partial \xi}\right)^{2}+\left(\frac{\partial \mathrm{p}}{\partial \theta}\right)^{2}}
$$

where $\eta$ is the viscosity, $\underline{\mathbf{u}}_{m}$ is the velocity vector in the midsurface, $\mathbf{u}_{\xi}$ is the velocity component parallel to $\mathrm{P}^{*} \xi$ (stretching direction) and $\mathrm{u}_{\theta}$ is parallel to $\mathrm{P}^{*} \theta$ (twisting direction).

The next step is to calculate the air drag force acting on the parison. Along the free-surface of the parison, the shear stress due to the drag from the surrounding air is computed as:

$$
\tau=\eta \dot{\gamma}(\varsigma)
$$

The force due to the pressure acts normal to the parison surface, i.e., oriented along $\mathrm{P}^{*} \zeta$, while the force due to the shear stress acts tangentially and oriented with the shear direction. The tangential shear force per unit surface, $\underline{t}$, on the parison can be decomposed into a 
component $t_{\theta}$ parallel to the local twisting (circumferential) direction and the other $t_{\xi}$ oriented along the parison axis $\mathrm{P} * \xi$ (stretching direction, see Figure 3 ).
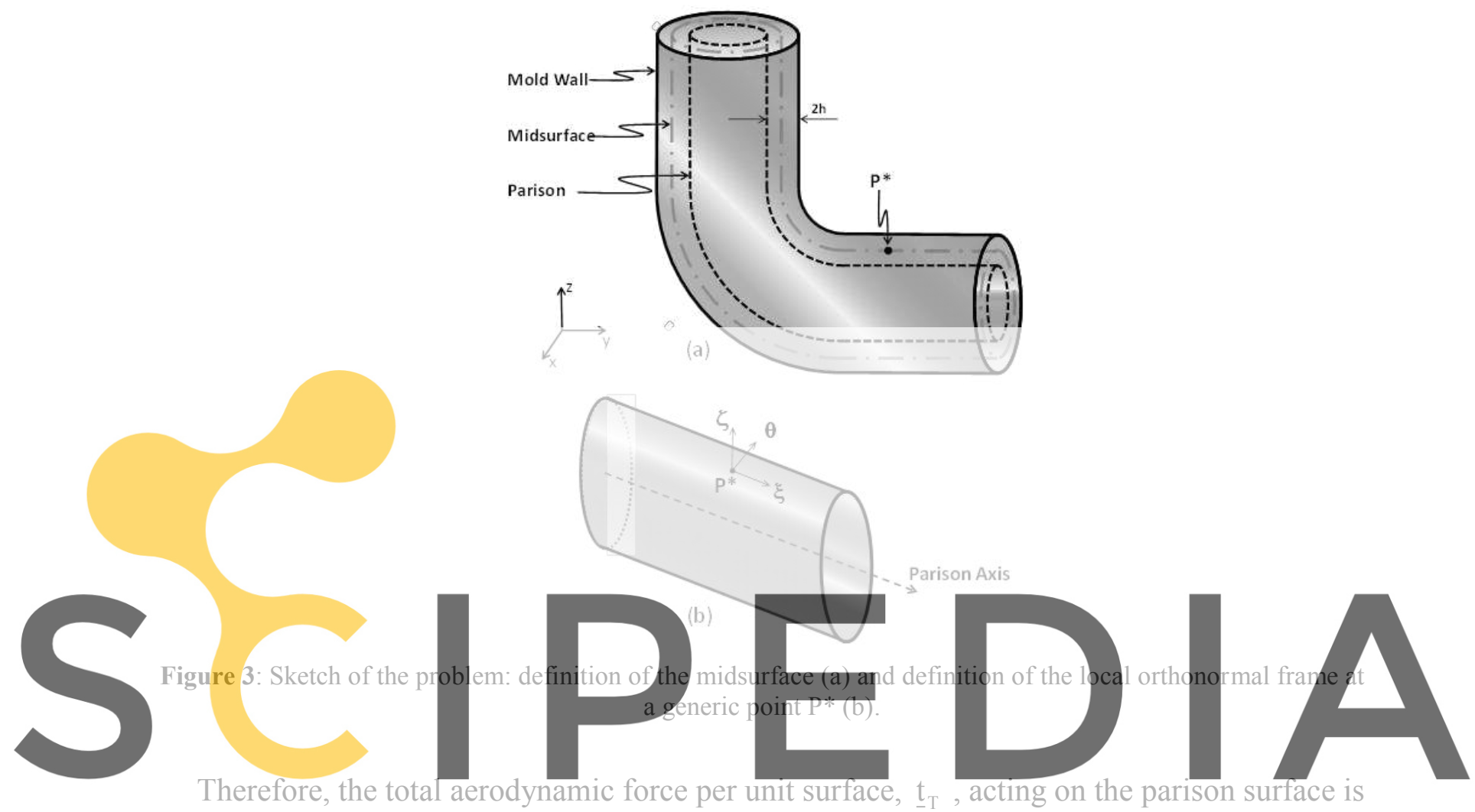

Register forpfree atshttps//www.scipedia.com to download the version without the watermark

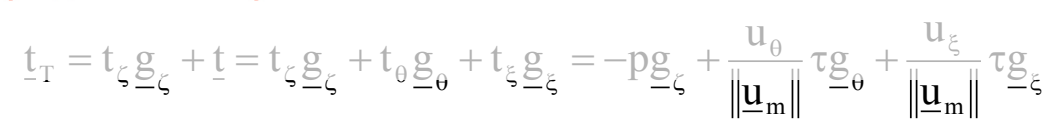

The air drag force $\underline{t}_{T}$ is exchanged from fluid to solid model at each time step.

\subsection{Equilibrium equations}

The material description for the principle of virtual work, i.e., the weak form of the equilibrium equations, involving the second Piola-Kirchhoff stress tensor $\mathrm{S}$ through the membrane force $\mathrm{N}$, the bending moment $\mathrm{M}$, the variation of the membrane strain tensor $\delta \mathrm{E}$ and the variation of the curvature tensor $\delta \chi$ can be expressed as [2]:

$$
\delta \mathrm{W}(\underline{\mathrm{u}}, \delta \underline{\mathrm{u}})=\int_{\Omega_{0}}(\mathrm{~N}: \delta \mathrm{E}+\mathrm{M}: \delta \chi) \mathrm{d} \Omega_{0}-\int_{\Omega_{0}} \underline{\mathrm{B}} \delta \underline{\mathrm{u}}(\mathrm{t}) \mathrm{d} \Omega_{0}-\int_{\partial \Omega} \underline{\mathrm{t}}_{\mathrm{T}}(\mathrm{t}) \delta \underline{\mathrm{u}}(\mathrm{t}) \mathrm{dA}=0
$$

where $\underline{\mathrm{u}}$ is the displacement field, $\Omega_{0}$ and $\partial \Omega$ stand for the volume of the initial configuration and the surface of the deformed configuration, respectively, $\underline{t}_{T}(t)$ is the Eulerian contact force acting on an infinitesimal deformed body surface dA. The derived 
variational principle is nonlinear in the displacement vector field $\underline{u}$. Therefore, we have to linearize the problem to achieve update formulas which are linear in every iteration step.

The rotation-free basic shell triangular (BST) finite element proposed by Onate and Flores [9] is used to accurately describe the bending deformation of the parison occurring during the suction stage. It has no rotational DOFs.

\subsection{Constitutive model}

As the suction process also involves stretching, bending, twisting and sliding of the parison within the mold cavity, the deformations of the parison during the process are modeled with an integral viscoelastic constitutive equation of the K-BKZ type [10]:

$$
\sigma(t)=-p I+\frac{1}{1-\theta} \int_{0}^{t} m(s) H\left(I_{1}, I_{2}\right)\left[C^{-1}(t-s)+\theta C(t-s)\right] d s
$$

where $\sigma$ is the Cauchy stress tensor, $\mathrm{p}$ is the pressure, $\theta$ is a parameter that refers to the second normal stress difference in the deformation (biaxial effect), $\mathrm{C}(\mathrm{t}-\mathrm{s})$ is the right CauchyGreen relative strain tensor, $\mathrm{C}^{-1}(\mathrm{t}-\mathrm{s})$ is the Finger strain tensor, $\mathrm{H}$ is the damping function, and $\mathrm{m}(\mathrm{s})$ the memory function, given by:

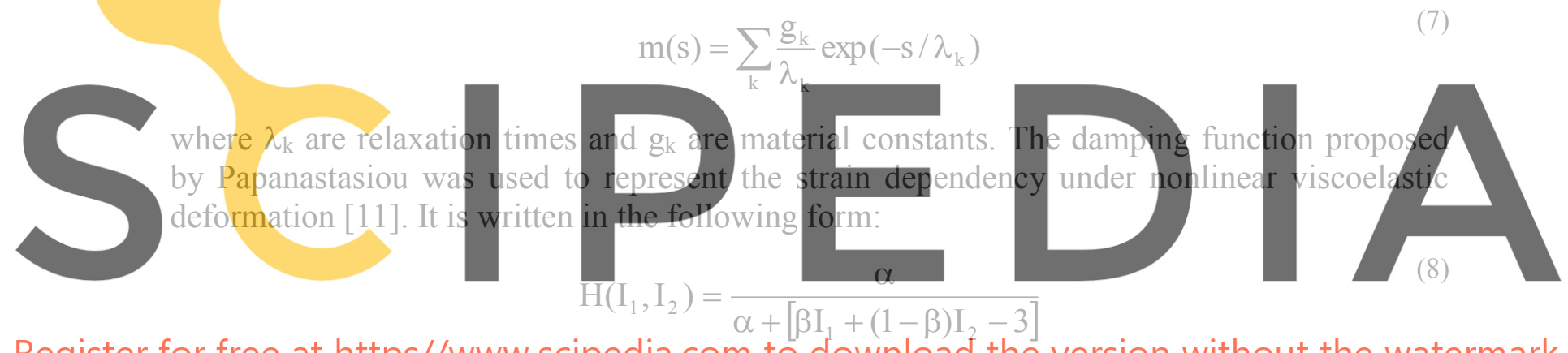

Register for free at https//www.scipedia.com to download the version without the watermark where $\alpha$ and $\beta$ are damping coefficients (material parameters) and $I_{1}$ and $I_{2}$ are invariants of $\mathrm{C}(\mathrm{t}-\mathrm{s})$ defined as follows:

$$
\mathrm{I}_{1}=\operatorname{tr}\left[\mathrm{C}^{-1}(\mathrm{t}-\mathrm{s})\right], \quad \mathrm{I}_{2}=\operatorname{tr}[\mathrm{C}(\mathrm{t}-\mathrm{s})]
$$

\subsection{Coupling method between fluid and structure models}

To complete the governing equations for the fluid-structure problem, it remains to model the interaction between the flow and the structure, i.e., to set corresponding boundary conditions on the fluid-structure interface.

The resolution is performed in a decoupled fashion using an iterative scheme, based on a fixed-point method. At each time step, the parison deformation problem is first solved with known air drag forces for the new position and shape of the parison in the mold, and then the fluid dynamics problem is solved on the new annular air flow domain for the air drag forces on the parison.

As described in the preceding sections, there are two fluid forces acting on the parison surface, i.e., the pressure and the shear forces. At time step $t_{n}$, the total aerodynamic forces are 
computed by solving the Hele-Shaw equation in the current annular air flow domain from the knowledge of the parison position in the mold cavity, which yields:

$$
\underline{\mathrm{t}}_{\mathrm{T}}=-\mathrm{pg}_{\zeta}+\frac{\mathrm{u}_{\theta}}{\left\|\underline{\mathrm{u}}_{\mathrm{m}}\right\|} \tau \underline{\mathrm{g}}_{\theta}+\frac{\mathrm{u}_{\xi}}{\left\|\underline{\mathrm{u}}_{\mathrm{m}}\right\|} \tau \underline{\mathrm{g}}_{\xi}
$$

The total aerodynamic force is then applied on the parison surface and the new position of parison is determined by solving the solid mechanic problem. When the parison deforms under the aerodynamic force, the annular air flow domain also deforms as the annular gap, $2 \mathrm{~h}(\xi, \theta)$, between the parison surface and the mold cavity is modified. This leads, at time step $t_{n+1}$, to a change in the flow field, i.e., the velocity, pressure and shear stresses, which are subsequently applied on the parison surface.

\section{CASE STUDY: PARISON SUCTION IN A "U" DUCT MOLD CAVITY}

We consider the case of parison suction in a "U" duct mold cavity shown in Figure 4, and analyze the effect of various parameters on the parison deformation during the process. The geometry of the duct mold of $50 \mathrm{~mm}$ diameter in which the parison is sucked belongs to a single plane as shown in Figure 4. The polymer investigated in this study is the HDPE Lupolen, grade 4261A [2].

The initial thickness and diameter of the parison segment at die exit are respectively, $2 \mathrm{~mm}$ and $30 \mathrm{~mm}$. Two cases are analyzed. The free extrusion
simultaneous extrusion-suction during which a suction air $\mathrm{f}$
sliding motion of the parison within the duct mold cavity.
which corresponds to an average annular air flow velocity of
Such a value is largely below its critical value for the turbule
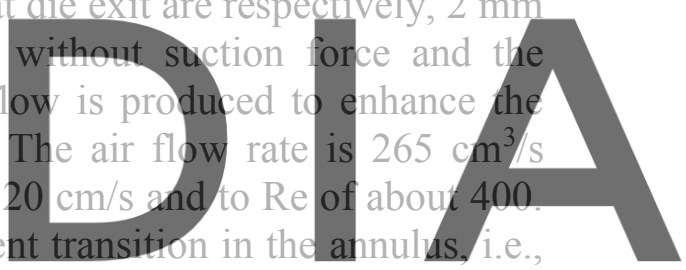

$\mathrm{Re}_{\mathrm{c}}=2000$. The air viscosity is set to $10^{-5} \mathrm{Pas}$ and its density $\rho$ to $1 \mathrm{~kg} / \mathrm{m}^{3}$. A small air

Register forefpere at hetps parison. The difficulty of this problem comes from the fluid-structure interaction and also from the sliding contact between the parison and the mold surface. Information has to be exchanged between both models (fluid and structure) at every time step. The flow domain is updated at each time step based on the shape and position of the parison in the mold cavity.

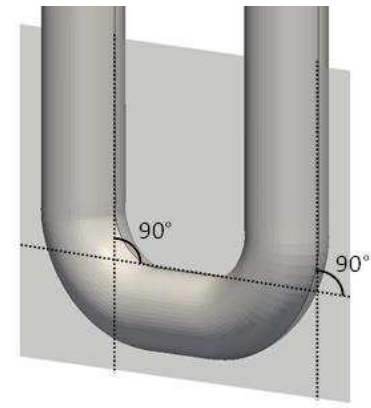

(a)

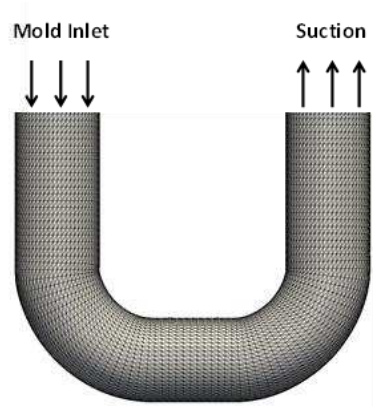

(b)

Figure 4: "U" shape duct mold geometry belonging to a single plane (a) and finite element mesh highlighting the mold inlet and suction direction (b). 
Figure 5 presents early parison shapes at the beginning of the suction process and the corresponding path within the duct mold, highlighting the effect of the air drawing force. First, the parison arrives from the extrusion head and is brought into the "U" duct mold cavity at the mold inlet and simultaneously extruded and drawn inside the cavity (Figure 5 at time $t_{1}$ ). Then, the parison follows two different paths that depend on the air drawing force. In the free extrusion, without air drawing force as shown in Figure 5a at two stages $\left(t_{1}\right.$ and $\left.t_{2}\right)$, the parison remains straight during extrusion before it hits the exposed points of the mold surface along the extrados of the elbow (Figure 5a at stage $t_{2}$ ). However, when the air drawing force is present (Figure $5 b$ at stage $t_{2}$ ), the parison already starts to bend as it approaches the elbow due the air drag on it.

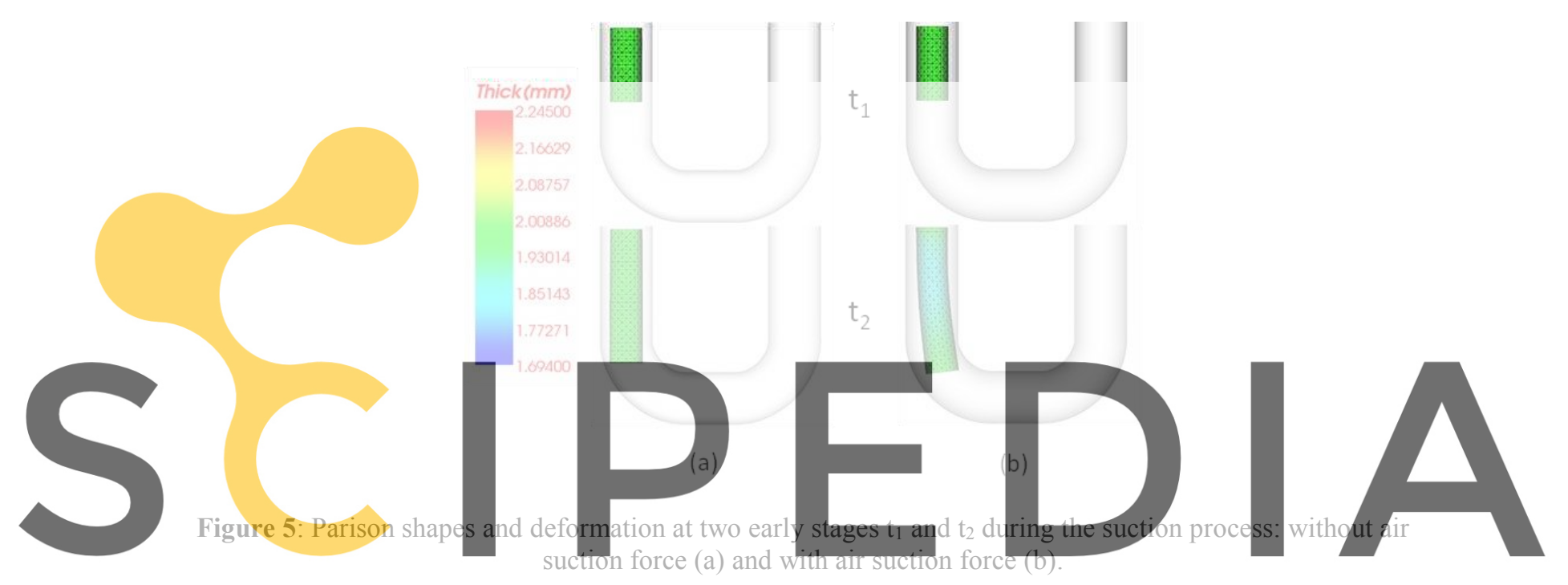

\section{Register for free at https / fwww scipedia com to download the version without the watermark}

the process are shown in Figure 6. This figure is the continuation of the previous figure (Figure 5). In the free extrusion, without air drawing force as shown in Figure 6a at three different stages ( $t_{3}$ to $t_{5}$ ), the parison deviates from its trajectory only after hitting the lower part of the mold (extrados mold surface, Figure 6a at stage $t_{3}$ ). At this point it starts to bend while sliding along the mold cavity surfaces (Figure $6 a$ at stages $t_{3}$ to $t_{5}$ ). On the other hand, when the air drawing force is present, the parison early moves away from the central axis and starts to bend due to air drag on it (Figure 6b at stage $t_{3}$ ). Hydrodynamic forces deform the parison and consequently the air flow domain. Then, the parison follows a completely different path, corresponding to the upper region of the "U" duct mold surface. At the end of the suction phase, the parison has almost completely matched the shape of the upper surface of the "U" duct mold due to the air drawing force. In the course of suction, the parison never touches the bottom surface of the mold. Although the same quantity of material has been extruded, the final length of the parison is considerably increased because of the large stretching deformation experienced during suction (Figure 6 at stage $t_{5}$ ). Furthermore, the surfaces of the parison already in contact with the mold cavity surfaces at the end of suction (Figure 6 at stage t5) $_{5}$ will almost exhibit no additional deformation during the subsequent 
stage of inflation, which may have a large effect on the final thickness distribution of the product. In fact, the inflation stage involves complex displacements and thickness nonuniformities of final product.

We shall continue with the analysis of the flow behavior around the parison during the suction process. The average flow velocity vectors in the gap between the mold and the parison at stage $t_{5}$ during suction are shown in Figure 7. It can be seen from Figure 7 that the air flow from the mold inlet is considerably reduced on the intrados surface with its velocity decreasing. We notice how the air flow gets around the parison in the first intrados, as the parison gets closer to the mold surface. While the flow field around the inlet region is almost aligned with the central axis of the parison, very complex shearing flow develops near the intrados region where strongest stretch is generated.
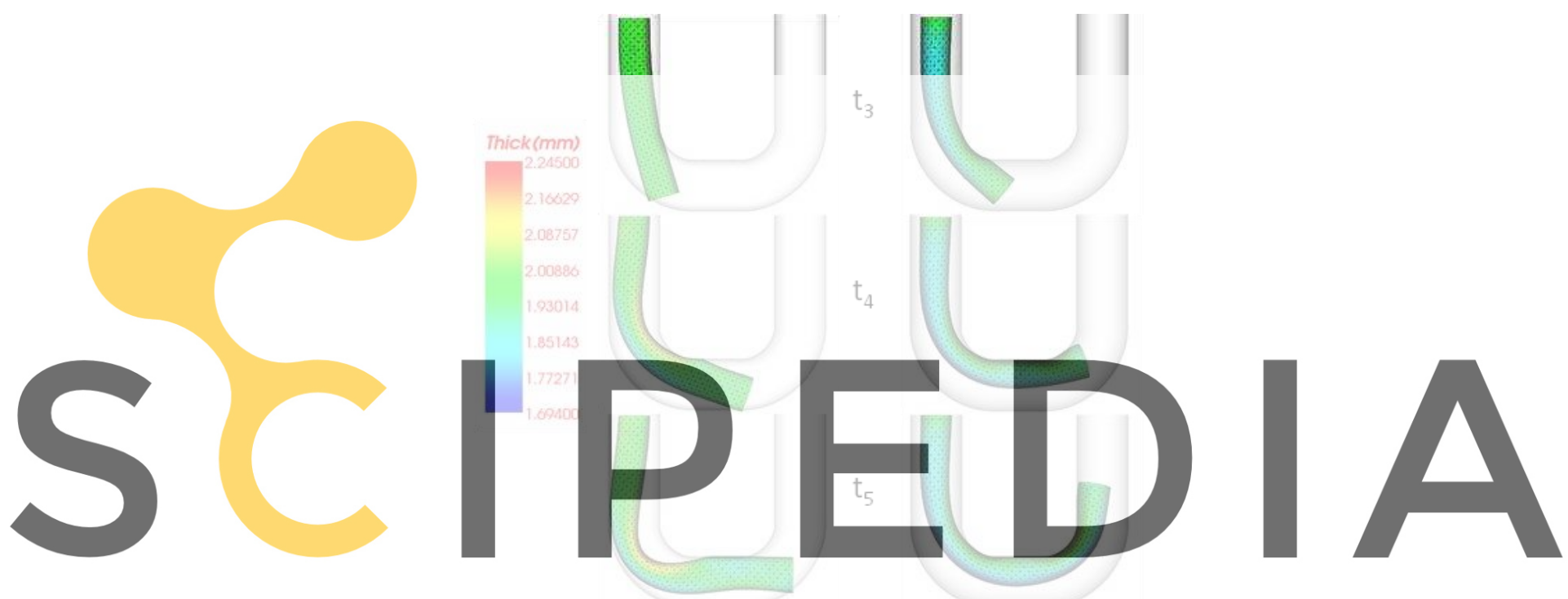

Register for free at https//www.scipedia.com to download the version without the watermark

\section{Figure 6: Parison shapes and deformation at later stages ( $t_{3}$ to $t_{5}$ ) during suction process: without air suction force (a) and with air suction force (b).}

Another quantity of interest is the twisting deformation experienced by the parison during suction. Such a twisting deformation can compromise the specific radial or circumferential variations of the parison thickness that are intentionally generated during extrusion. In this regard, let us consider the effect of parison/mold eccentricity on twisting deformation. Figure 8 defines the problem, where the parison center is displaced eccentrically in the $\mathrm{z}$ direction by eccentricity, $\mathrm{e}=-4 \mathrm{~mm}$, with respect to the center of the cross-section of the mold inlet. Notice that, the parison translation along the $\mathrm{z}$ axis is perpendicular to the $\mathrm{x}$ axis which is precisely oriented along the horizontal section of the duct mold.

Figure 9 shows twisting deformation caused by making the parison center eccentric with respect to the mold center. As long as the parison is centered with the mold, no twisting deformation is exhibited as shown in Figure 9a, and generatrix lines of the parison are aligned with the parison central axis at each stage. Conversely, when the parison is displaced eccentrically, the upstream flow around the parison is no longer symmetric with respect to the 
plane shown in Figure 4. The parison undergoes complex shear stresses, which induce twisting moment. As a consequence, the parison twists clockwise (from left to right) as shown in Figure 9b, in accordance with the shear force experienced by the parison.

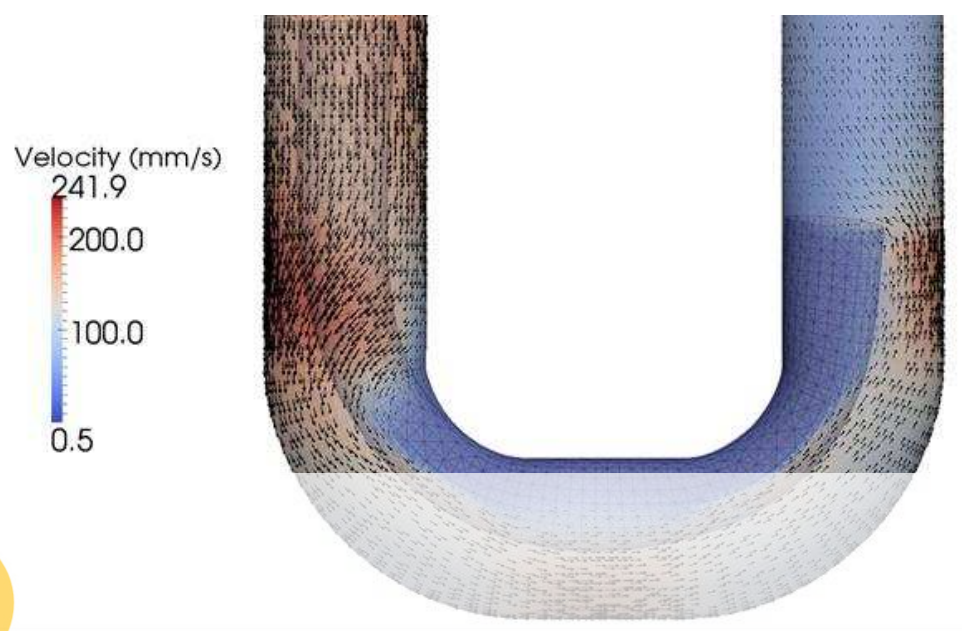

Figure 7: Average flow velocity vectors in the gap between the mold cavity and the parison surface at a given stage during suction.

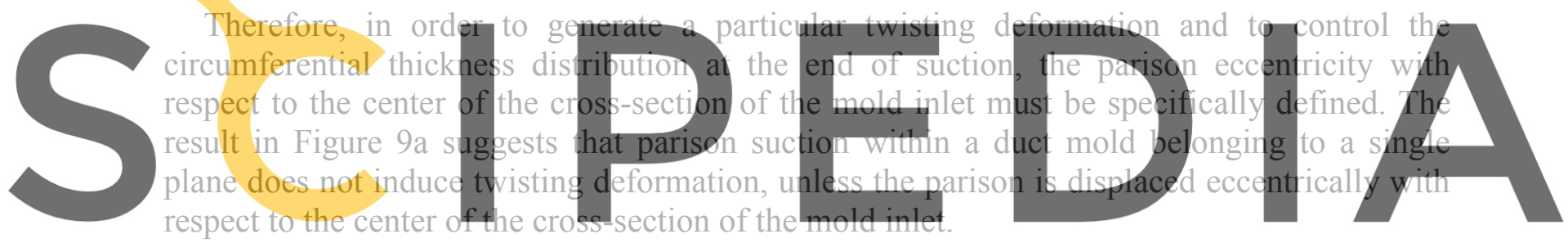

Register for free at https//www.scipedia.com to download theriversion without the watermark
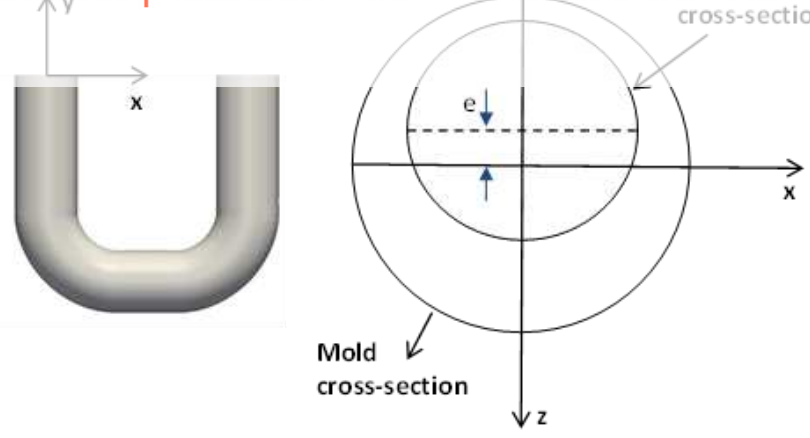

(a)

(b)

Figure 8: "U" duct mold geometry with axis (a) and cross-section of the parison showing the eccentricity with respect to the center of the cross-section of the mold inlet (b).

A more quantitative inspection of the rotation undergone by the parison during the suction phase can be done by tracking some selected points of the parison from the mold inlet to the 
end of suction. We selected 3 points at the mold inlet as shown in Figure 10. The angle between two successive points at the inlet is 60 degrees. The results in Figure 10 show the rotation experienced by those selected points at stage $t_{5}$ during suction. In particular, the final location of points 1 and 2 shows that they have undergone a total rotation of about 55 degrees with respect to their initial circumferential position.
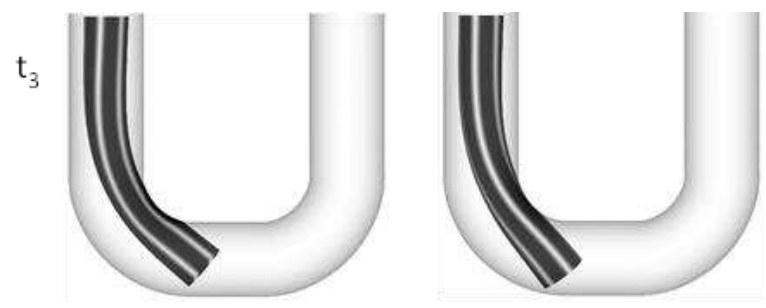

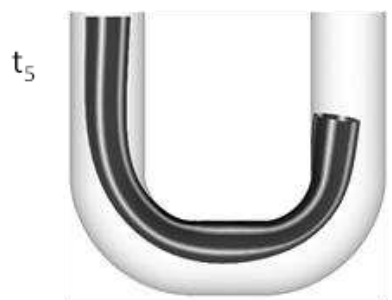

(a)

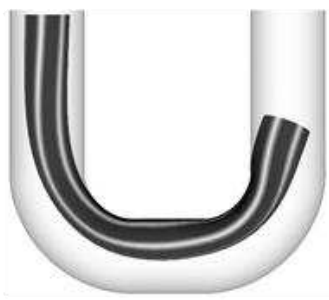

(b)

Figure 9: Parison deformation and generatrix lines showing the effect of parison/mold eccentricity on twisting deformation exhibited by the parison at two different stages $t_{3}$ and $t_{5}$ during suction: without parison eccentricity (a) and with parison eccentricity e $=-4 \mathrm{~mm}$ shown in Figure 8 (b).

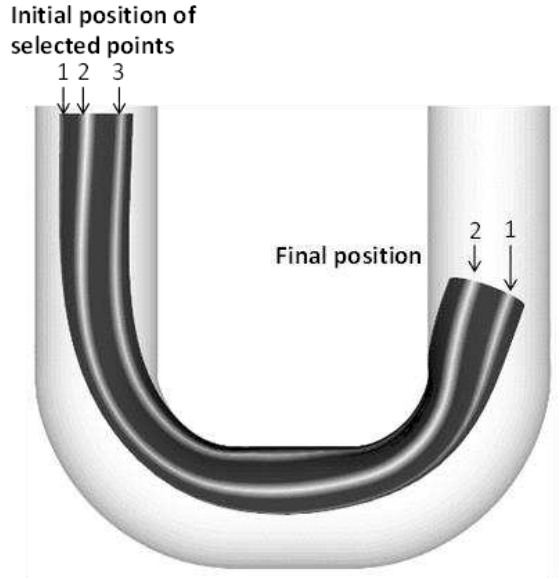

(a)

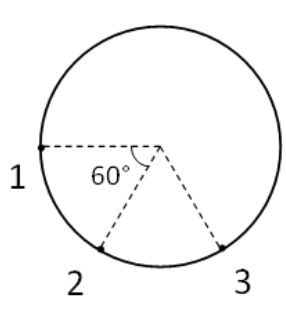

(b)

Figure 10: Generatrix lines showing the rotation undergone by the parison at stage $t_{5}$ (as reported in Figure $9 b$ ), with eccentricity e $=-4 \mathrm{~mm}$. Points 1 and 2 have undergone a rotation of about 55 degrees from the mold inlet to the mold exit (a) and angle between successive selected points at mold inlet is 60 degrees (b). 


\section{CONCLUSIONS}

We carried out a numerical study of the suction blow molding process based on a fluidstructure interaction model, with an emphasis on the suction phase. Overall, the present numerical model is capable of predicting the flow around the parison and deformation of the parison during suction, at least, in qualitative manner. The results obtained allow identifying a clear correlation between the flow conditions and the twisting deformation. Our numerical results suggest that parison suction within a duct mold belonging to a single plane does not induce twisting deformation, unless the parison is displaced eccentrically with respect to the center of the cross-section of the mold inlet. Such twisting deformation may compromise the specific radial and circumferential variations in parison thickness that are intentionally generated during extrusion and should be accurately predicted to prevent defects in the final product. Among the major parameters that contribute to twisting deformation we can cite: the parison/mold eccentricity, the geometry of the duct mold cavity and the air suction speed.

\section{REFERENCES}

[1] Caviezel, H., Hirt, M. and Kettl, R. Suction blowmold for Producing Extrusion SuctionBlowmolded Plastic Molded Parts. US Patent. (2008) US 2008/0171163 A1.

[2] Kabanemi K.K. and Marcotte J.P. Numerical Simulation of Suction Blow Molding Process for Producing Curved Ducts. Polym. Eng. Sci. (2019) 59:418-434.

[3] Kabanemi K.K. and Marcotte J.P. A Level Set Method for Simulating Wrinkling of Extruded Viscoelastic Sheets. Polym. Eng. Sci. (2020) 60:1662-1675.

[4] Luo, X.L. and Mitsoulis, E. Memory Phenomena in Extrudate Swell Simulations for Annular Dies. J. Rheol. (1989) 33:1307-1327.

[5] Laroche, D., Kabanemi, K.K., Pecora, L. and DiRaddo, R.W. Integrated Numerical Modeling of the Blow Molding Process. Polym. Eng. Sci. (1999) 39:1223-1233.

[6] Debbaut, B. and Homerin, O. A Comparison between Experiments and Predictions for the Blow Molding of an Industrial Part. Polym. Eng. Sci. (1999) 39:1812-1822.

[7] Dou, H.S., Khoo, B.C. and Tsai, H.M. Determining The Critical Condition For Turbulent Transition In A Full-Developed Annulus Flow. J. Petrol Sci. Eng. (2010) 73:41-47.

[8] Dupret, F. and Vanderschuren, L. Calculation of the Temperature Field in Injection Molding, AIChE Journal. (1988) 4:1959-1972.

[9] Flores, F.G. and Oñate, E. A Basic Thin Shell Triangle with only Translational DOFs for Large Strain Plasticity. Int. J. Numer. Meth. Engng. (2001) 51:57-83.

[10] Bernstein, B., Kearsley, E. and Zapas, L.J. A Study of Stress Relaxation with Finite Strain. Trans. Soc. Rheol., (1963) 7:391-410.

[11] Papanastasiou, A.C., Striven, L.E. and Macosko, C.W. An Integral Constitutive Equation for Mixed Flows: Viscoelastic Characterization. J. Rheol. (1983) 27:387-410. 